\title{
Renal pelvis and ureteropelvic junction incarceration in a Grynfeltt-Lesshaft hernia: a case report and review of the literature
}

\author{
Saadat Mehrabi, Mohammad Javad Yavari Barhaghtalab* (10) and Mehdi Babapour
}

\begin{abstract}
Background: Grynfeltt-Lesshaft hernia is a kind of lumbar abdominal wall hernia in which clinical presentations may vary from an asymptomatic bulge in the lumbar area to a symptomatic lumbar mass with back pain. It has been accepted to be a rare entity, and incarceration of the kidney through this hernia is shown to be very rare, and very few previous cases have been reported in this regard.

We present a case of renal pelvic and ureteropelvic junction incarceration in a Grynfeltt-Lesshaft hernia and provide an overview of the existing literature on it.

Case presentation: A 76-year-old lady presented to the outpatient clinic with the chief complaint of right flank pain and swelling. Computed tomography (CT) scan of the abdomen was revealed a large herniated sac $(60 * 30$ $\mathrm{mm}$ ) in the upper lumbar triangle with protrusion of retroperitoneal and omental fat, right renal pelvis, ureteropelvic junction and proximal ureter with consecutive hydronephrosis. Herniated retroperitoneal and omental fat was reduced, and closure of the abdominal wall defect was done using retro-muscular Mesh and was fixed to the fascia. The patient was discharged $24 \mathrm{~h}$ after the surgery without any complications.
\end{abstract}

Conclusion: Kidney herniation through the lumbar triangle is extremely rare, and the diagnosis requires careful clinical evaluation. CT scan is the modality of choice for the assessment. Management through surgery should be done in symptomatic patients.

Keywords: Grynfeltt-Lesshaft hernia, Renal pelvic, Ureteropelvic junction, Incarceration, Hydronephrosis, Muscular or sublay mesh

\section{Background}

The lumbar abdominal wall hernia is uncommon. In this kind of hernia retroperitoneal (kidneys, urinary bladder, and ascending or descending colon) and intraperitoneal (small bowel, omentum, preperitoneal fat, stomach, spleen, etc) elements bulge through a defect in the dorsal posterolateral abdominal wall (upper lumbar or the Grynfeltt-Lesshaft triangle) [1-6].

\footnotetext{
* Correspondence: mj.yavari.barhaghtalab@gmail.com Department of General Surgery, Shahid Beheshti Hospital, Yasuj University of Medical Sciences, Yasuj, Iran
}

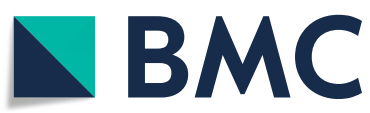

(c) The Author(s). 2020 Open Access This article is licensed under a Creative Commons Attribution 4.0 International License, which permits use, sharing, adaptation, distribution and reproduction in any medium or format, as long as you give appropriate credit to the original author(s) and the source, provide a link to the Creative Commons licence, and indicate if changes were made. The images or other third party material in this article are included in the article's Creative Commons licence, unless indicated otherwise in a credit line to the material. If material is not included in the article's Creative Commons licence and your intended use is not permitted by statutory regulation or exceeds the permitted use, you will need to obtain permission directly from the copyright holder. To view a copy of this licence, visit http://creativecommons.org/licenses/by/4.0/ The Creative Commons Public Domain Dedication waiver (http://creativecommons.org/publicdomain/zero/1.0/) applies to the data made available in this article, unless otherwise stated in a credit line to the data. ternal oblique muscle laterally, border of the erector spinae muscle group (quadratus lumborum) medially, the 12th rib superiorly, transversalis fascia aponeurosis on the floor, latissimus dorsi muscle on the roof $[1,7,8]$. The weakening of the transversalis fascia and the aponeurosis of the transversus abdominis is the reason for this problem [9] (Fig. 1).

It's more frequent in men between 50 and 70 years old and is more prevalent on the left side of the abdomen [10]. Risk factors are elderly, obesity, muscular atrophy, and chronic obstructive pulmonary disease (COPD) or 


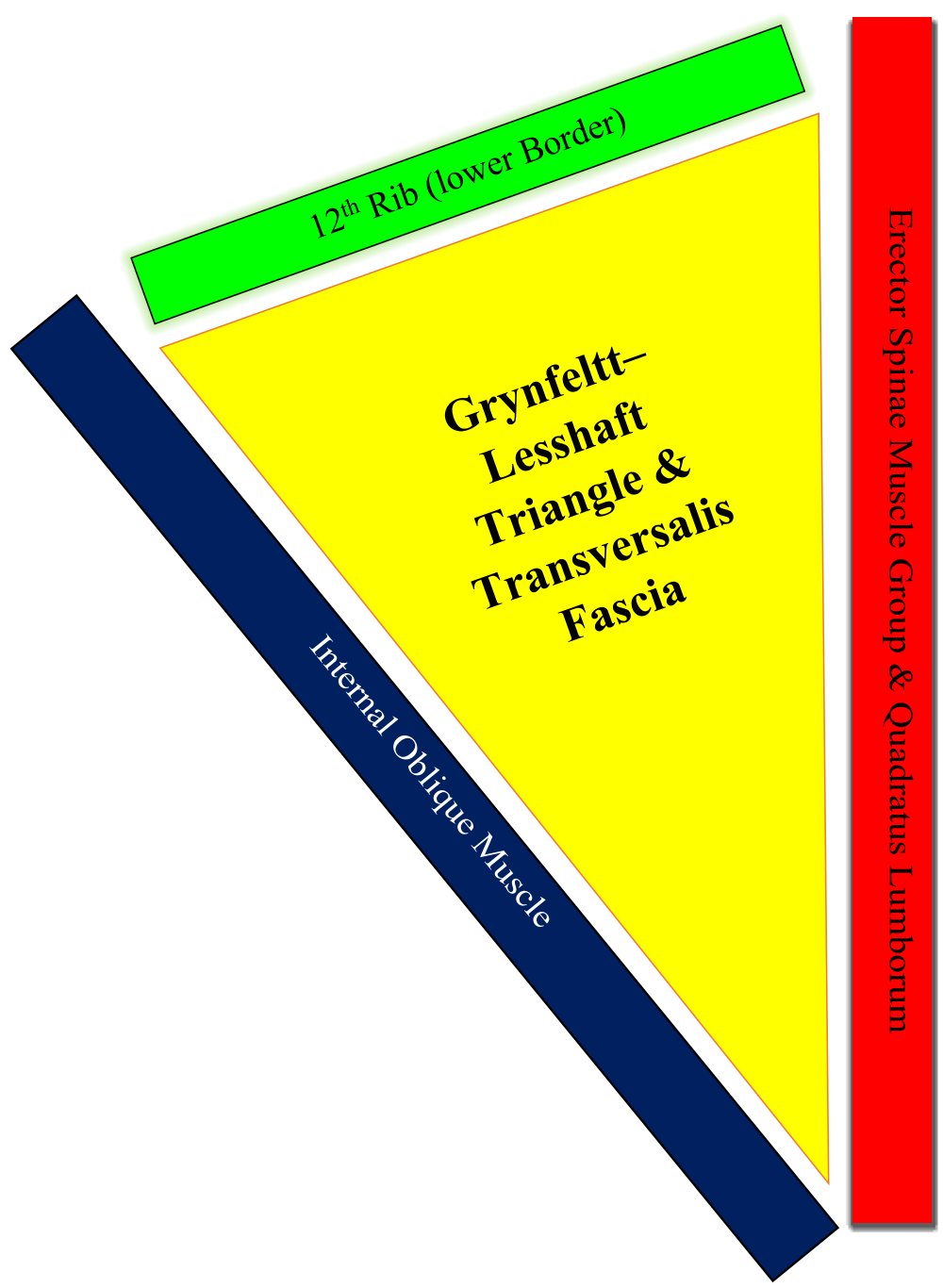

Fig. 1 A schematic showing the parameters of the Grynfeltt-Lesshaft Hernia

any other condition that yields in increasing intraabdominal pressure [11].

Many surgeons are unfamiliar with lumbar hernias, which may cause a delay in the diagnosis of the disease $[3,7]$. Clinical presentations may vary from an asymptomatic bulge in the lumbar area to a symptomatic lumbar mass with back pain or vague abdominal symptoms and are related to the protruded contents [4]. This could have iatrogenic, congenital, and traumatic causes, while most of the patients have primary acquired hernias $[1,4]$. Lumbar hernias have been misdiagnosed as lipomas [4, 7, 12-14], muscle strains, fibromas, abscesses, and kidney tumors, causing increased morbidity due to the incorrect diagnosis [3]. It is recommended to repair these hernias electively if there are no contraindications [4]. It has been said that there would be just only one case of lumbar hernia in a general surgeon's life to operate $[13,15]$.
A lumbar hernia is an unusual defect, and only 300 cases of primary lumbar hernias have been reported since the first case report by Garangoet in 1731 [13, 14, 16]. Their diagnosis is vital due to their substantial possible complications such as incarceration and strangulation in 25 and $8 \%$ of patients retrospectively [17]. So as this kind of hernia has been accepted to be a rare entity, incarceration of the kidney through this hernia is shown to be very rare, and very few previous cases have been reported in this regard [18-21].

We present a case of renal pelvic and ureteropelvic junction herniation in a Grynfeltt-Lesshaft hernia and provide a clear overview of the existing literature on it.

\section{Case presentation}

A 76-year-old lady presented to the outpatient clinic with the chief complaint of right flank pain and swelling that protrudes with efforts, reduced mostly in resting 


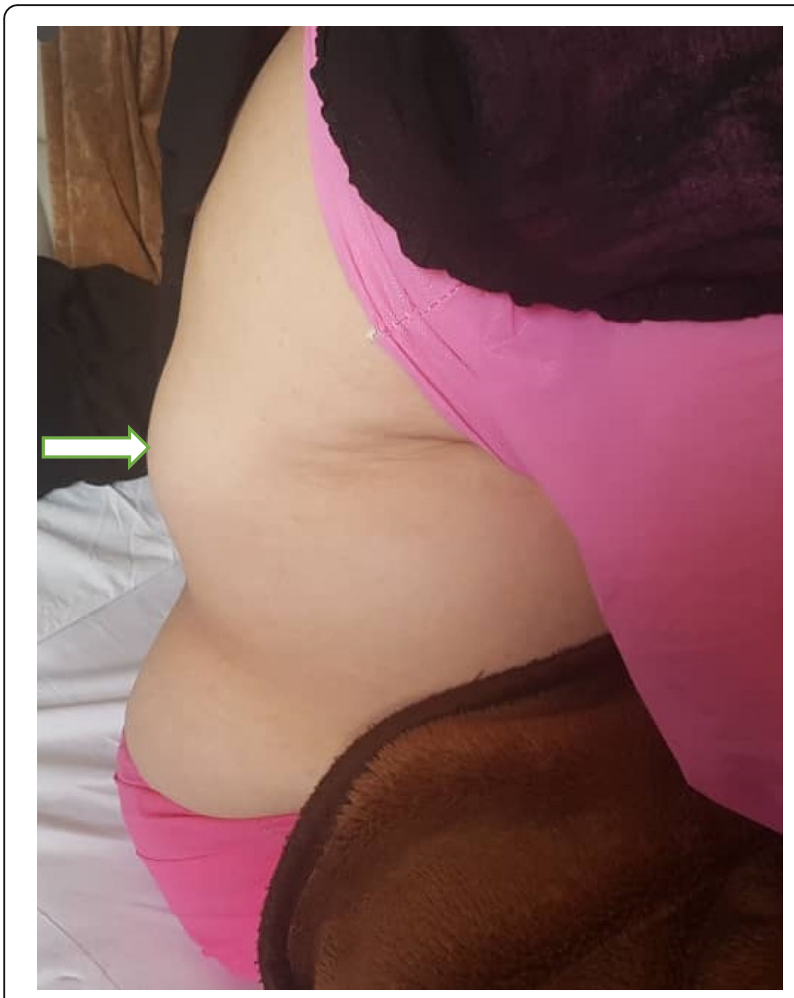

Fig. 2 Right lumbar Hernia in a 76-year-old woman is shown with a white arrow position and increasing in size for about 2 months before hospital admission (Fig. 2). The bulging was not associated with gastrointestinal and urinary problems. The patient's past medical history was positive for diabetes mellitus (DM), hypertension (HTN) and hyperlipidemia (HLP), and an overweight body mass index (BMI) of 28.9. She underwent hysterectomy, laparoscopic cholecystectomy, and urinary bladder prolapse repair surgery previously. She did not have any history of back trauma and heavy lifting previously. She had three children born by vaginal delivery. She used metformin and losartan for medications. There was no family history of the hernia in her parents, siblings, and children. In the physical examination in standing position, we found a soft, mildly tender, irreducible, and smooth border-right lumbar mass (on right scapular line just below the costal margin) which protruded when coughing. No bowel sounds were auscultated on the hernia.

A computed tomography (CT) scan of the abdomen revealed a large herniated sac $(60 * 30 \mathrm{~mm})$ beneath the right 12th rib in the upper lumbar triangle with protrusion of retroperitoneal fat, right renal pelvis, ureteropelvic junction and proximal ureter with consecutive hydronephrosis extended to the posterior aspect of the kidney (Figs. 3 and 4). After conducting preoperational evaluations and informed consent, the patient was operated under general anesthesia in a right lateral position. A transverse incision about $10 \mathrm{~cm}$ was made on the

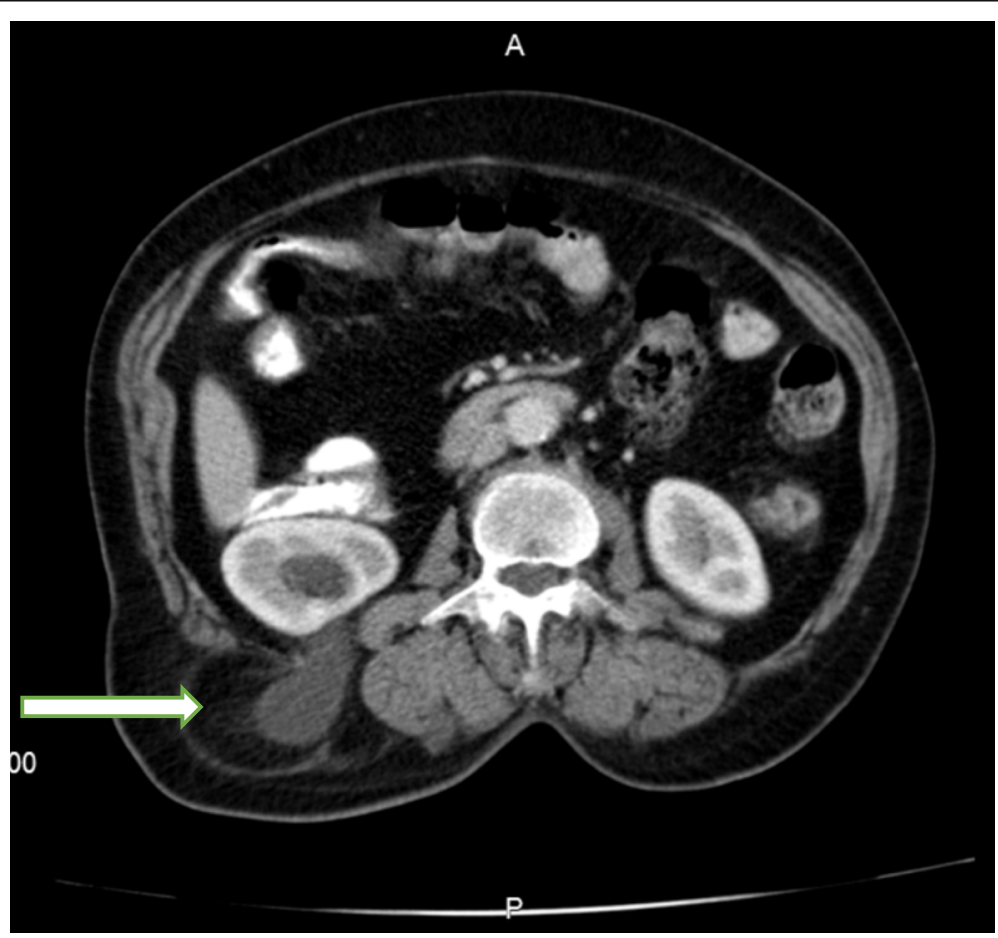

Fig. 3 Spiral CT scan without contrast: herniated sac containing retroperitoneal and omental fat, and right renal pelvis (white arrow) 


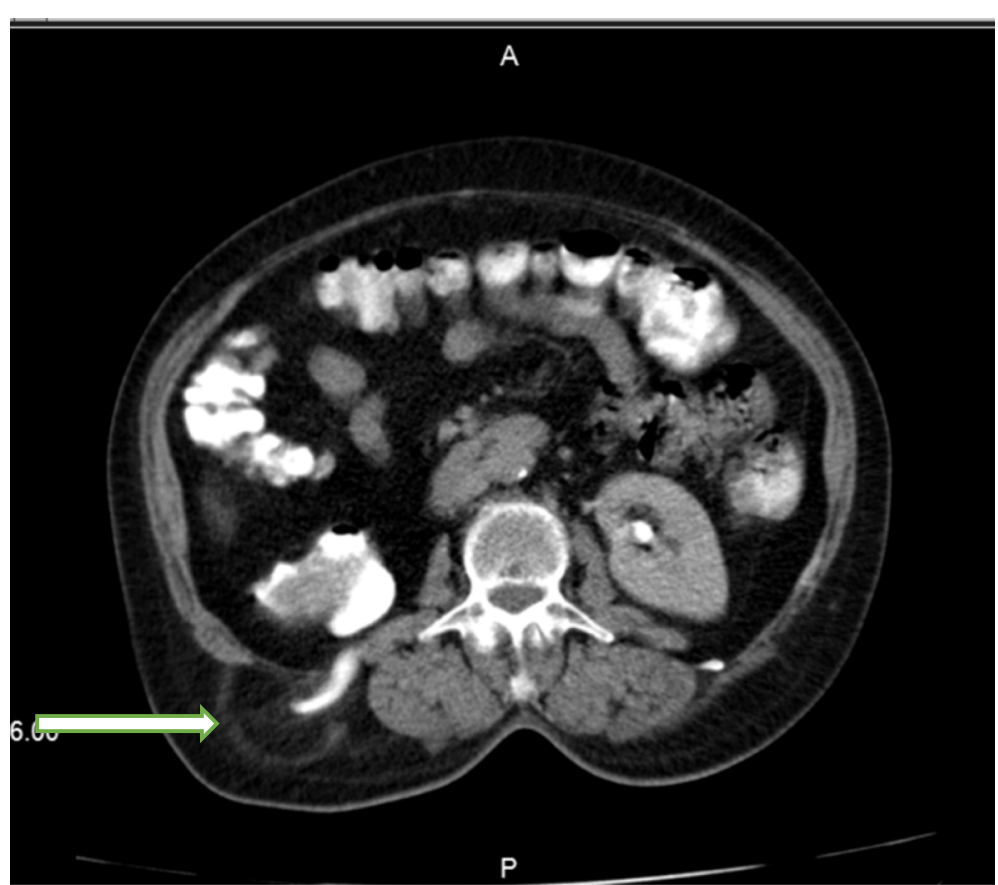

Fig. 4 Spiral CT scan with intravenous (IV) contrast: herniated sac containing right ureter (white arrow)

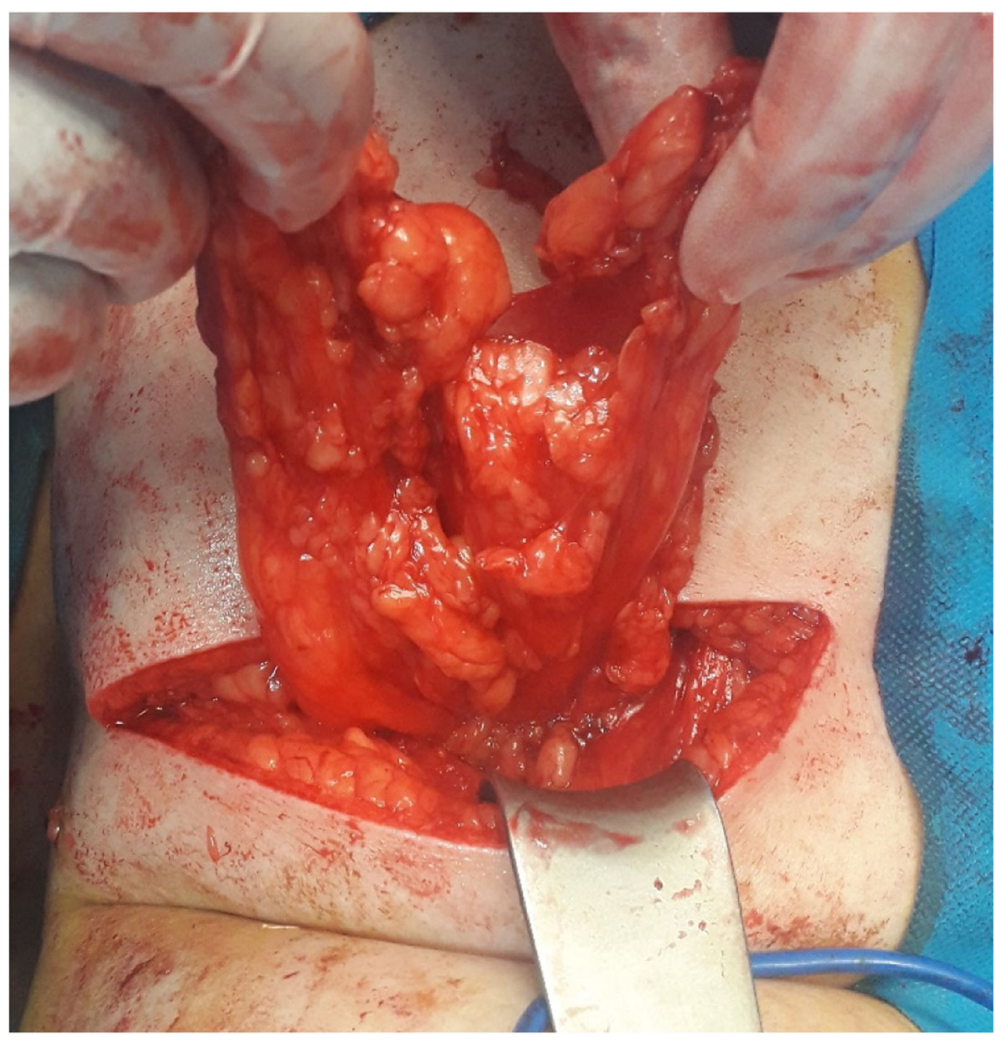

Fig. 5 Retroperitoneal and omental fat in the herniated sac in lumbar hernia 
bulging area. After dissection of skin, subcutaneous tissue, and muscle layer (latissimus dorsi), a hernia sac through a $3 \mathrm{~cm}$ defect was found. There was a herniated retroperitoneal and omental fat in the sac, so it was reduced back and closure of the abdominal wall defect was done using retro-muscular or sublay Monofilament Polypropylene Mesh (Paha ${ }^{\circ} 15 \mathrm{~cm}$ ) (Figs. 5, 6 and 7). Mesh was fixed to the fascia with non-absorbable interrupted sutures using a tension-free technique. The muscles and fascia were sutured separately with absorbable sutures, and the wound was closed. A drain catheter was not necessary to be placed. The operating time was 41 $\mathrm{min}$, there were no hospital postoperative complications, and we discharged the patient $24 \mathrm{~h}$ after the surgery. The patient was visited and followed up on the 7th, 30th' and 60th days after discharge from the hospital, and there were good results.

\section{Discussion and conclusions}

Lumbar hernias are rare congenital or acquired diseases ( $20 \%$ vs. $80 \%$ of the cases). Congenital hernias are seen in infants and children and are related to defects in the lumbar wall. Acquired hernias are divided into two groups: spontaneous (primary) hernias and secondary acquired hernias [8]. Our patient presented a primarily acquired hernia with protrusion of retroperitoneal fat, right renal pelvis, ureteropelvic junction, and proximal ureter. Reviewing the literature regarding herniation of the urinary system into the lumbar hernia has resulted in only five previous published reports. The first report presented by Presti et al. in which a 42 -year-old man had a 2-week history of intermittent right flank pain and total gross hematuria. CT scan showed a right lumbar hernia with a herniated kidney in, so then the surgical repair was done [18]. Fogarty et al. presented a 76-yearold woman with right flank pain and acute renal insufficiency. CT scan revealed herniation of retroperitoneal fat, right renal pelvis, and ureteropelvic junction through a lumbar hernia [19]. Cabello et al. presented a 79-yearold woman with a tender bulging in the left lumbar area and acute ureteral colic pain, who underwent CT scan and was diagnosed to have Grynfeltt's bilateral hernia

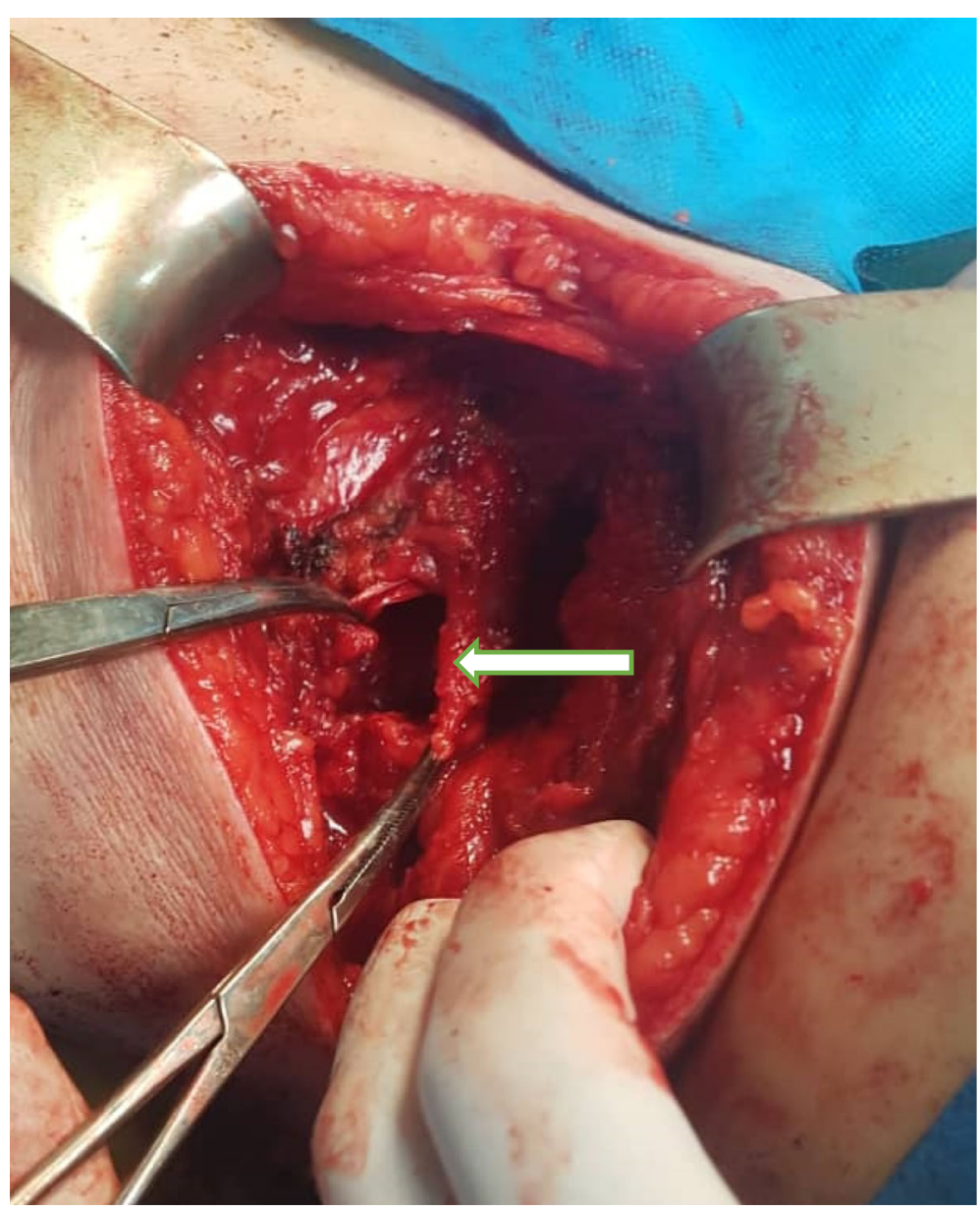

Fig. 6 A $3 \mathrm{~cm}$ defect through which herniation occurred (white arrow) 


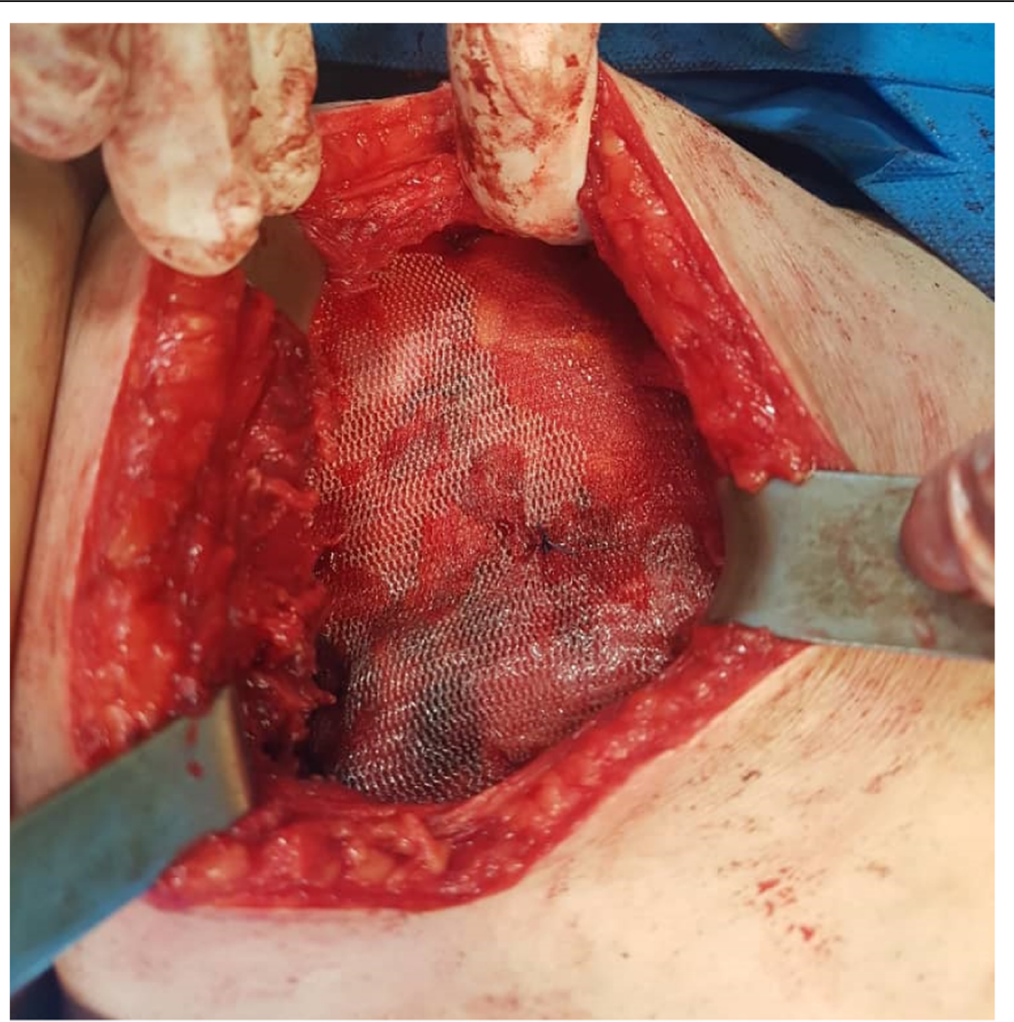

Fig. 7 Hernioplasty with Monofilament Polypropylene Mesh

and herniation of left renal pelvis and proximal ureter [20]. Miyazato et al. reported a 59-year-old woman a known case of Cushing's syndrome who underwent laparoscopic adrenalectomy and afterward developed with lumbar herniation of the left kidney [21]. Al Hooti et al. presented a 60-year-old woman with protrusion of the right kidney lower pole through the lumbar triangle 10 years after an open right pyeloplasty. She was successfully treated conservatively in clinic and received analgesics frequently for relief of mild pain without attempting operational repair [22]. The data from the previous and our current reports are summarized in Table 1.

Therefore, the majority of patients were female patients. The mean age of the patients was $65.33 \pm 5.342$ years (with a confidence level of 95\%). Pain and swelling were the dominant symptoms reported in all the patients. The pain was accompanied by gross hematuria, acute renal insufficiency, and acute renal colic pain in one patient each. The right side was more involved seen in 4 cases. Physical examination was mentioned in 4 cases, of which tenderness was found in three. Past medical history was positive for abdominal aortic aneurysm in one patient. Hypertension, diabetes, and hyperlipidemia were seen in two patients. Hypothyroidism, hyperuricemia, right adrenal Cushing's syndrome, left primary aldosteronism, right pelviureteric junction obstruction and overweight were found in one patient each retrospectively. Previous surgery history was positive in 4 cases. Laparotomy with partial right colectomy following a sharp injury, laparoscopic adrenalectomy, open right Anderson Hynes pyeloplasty and hysterectomy, laparoscopic cholecystectomy, and urinary bladder prolapse repair surgery was seen in one patient each retrospectively. CT scan was the modality used in all the cases. Intravenous urogram (IVU) was done in two patients, and an abdominal $x$-ray, mercaptoacetyltriglycine renal scan, and magnetic resonance imaging (MRI) were done in one patient each retrospectively. MRI was the dominant diagnostic modality used in a patient with post-laparoscopic adrenalectomy lumbar hernia. The kidney was protruded partially in all the patients. Beside, ureteropelvic junction, proximal ureter and retroperitoneal fat were seen in 2 cases each retrospectively. Urological complications were mentioned in 5 cases, of which pyelocaliectasis and hydronephrosis were seen in all the patients and ureteropelvic junction obstruction was seen in one patient.

Two patients underwent non-surgical analgesic management. Surgery was done in 4 cases, of which opened hernioplasty was done in three and was not mentioned in one. In a study done by Vagholkar et al., an open approach was implemented [23], similar to the method done in our study. They concluded that both laparoscopic and open 


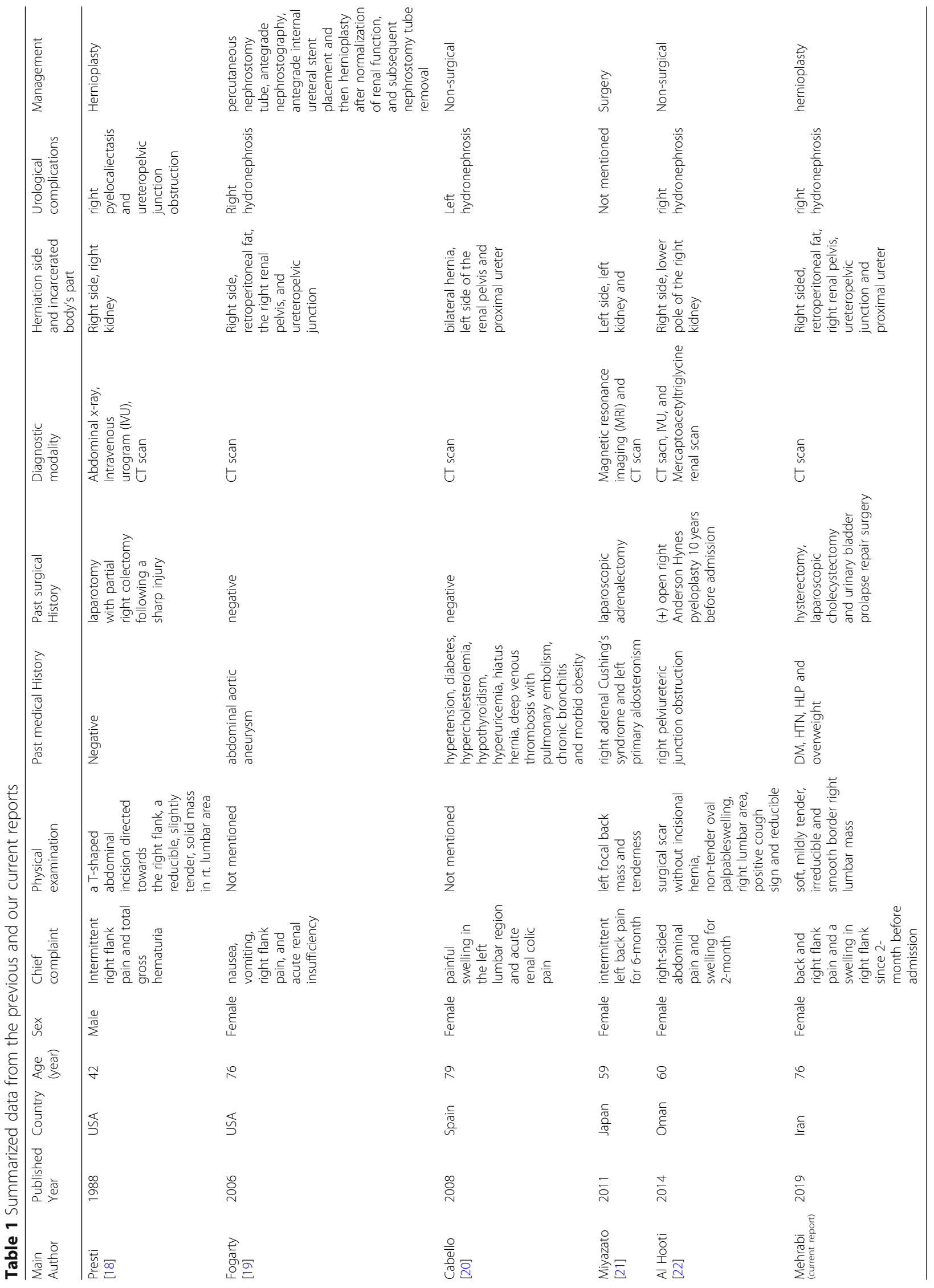


approaches could be done, although open mesh repair is an easier, safer, and more effective method of treating this uncommon surgical illness [23]. In two previous studies, Moreno-Egea et al. evaluated laparoscopic versus open repair in lumbar hernia surgery through some prospective studies $[24,25]$. They have found that results did not vary according to morbidity and recurrence rate, although it would reduce postoperative morbidity, pain, and early return to daily routine activities.

In one case, hernioplasty was done following normalization of renal function through percutaneous nephrostomy tube, antegrade nephrostography, antegrade internal ureteral stent placement, and subsequent nephrostomy tube removal.

To our best knowledge, this is one of the first reported cases and also the first literature review on acquired herniation of the renal pelvis and ureteropelvic junction through a Grynfeltt hernia with resultant hydronephrosis.

Kidney herniation through the lumbar triangle is extremely rare, and the diagnosis requires careful clinical evaluation. CT scan is the modality of choice for the assessment. Management through surgery should be done in symptomatic patients. Both laparoscopic and open approach can be done for treating this illness; however, an open approach is an easier and safer method.

\section{Abbreviations}

CT scan: Computed tomography scan; COPD: Chronic obstructive pulmonary disease; DM: Diabetes mellitus; HTN: Hypertension; HLP: Hyperlipidemia; BMI: Body mass index; IV: Intravenous; IVU: Intravenous urogram;

MRI: Magnetic resonance imaging

\section{Acknowledgments}

We all express our gratitude to the patient who kindly gave consent for this case to be presented in this paper. The authors also wish to thank Dr. Aida Iraji at the Central research laboratory, Shiraz University of Medical Sciences, Shiraz, Iran for her assistance in editing this manuscript.

\section{Authors' contributions}

Principal author: SM evaluated the patient clinically, operated the patient (main surgeon), read and revised the paper. Co-author: MJYB evaluated the patient clinically, helped to operate the patient (co-surgeon), prepared the first draft and revised the paper. Co-author: MB evaluated the patient clinically, and helped to operate the patient (co-surgeon). All authors read and approved the final manuscript.

\section{Funding}

Not received.

\section{Availability of data and materials}

The datasets used and/or analysed during the current study are available from the corresponding author on reasonable request.

\section{Ethics approval and consent to participate}

Not applicable

\section{Consent for publication}

Written informed consent was obtained from the patient for publication of this case report and any accompanying images. A copy of the written consent is available for review by the Editor-in-Chief of this journal.

\section{Competing interests}

The authors of this manuscript declare no competing of interests.
Received: 3 December 2019 Accepted: 5 May 2020

Published online: 25 June 2020

\section{References}

1. van Steensel S, Bloemen A, van den Hil LCL, van den Bos J, Kleinrensink GJ, Bouvy ND. Pitfalls and clinical recommendations for the primary lumbar hernia based on a systematic review of the literature. Hernia. 2019:23(1): 107-17. https://doi.org/10.1007/s10029-018-1834-9.

2. Macchi V, Porzionato A, Morra A, Picardi EEE, Stecco C, Loukas M, et al. The triangles of Grynfeltt and petit and the lumbar tunnel: an anatomoradiologic study. Hernia. 2017:21(3):369-76. https://doi.org/10.1007/s10029016-1509-3.

3. Suh Y, Gandhi J, Zaidi S, Smith NL, Tan M-Y, Khan SA. Lumbar hernia: A commonly misevaluated condition of the bilateral costoiliac spaces. Transl Res Anat. 2017;8-9:1-5. https://doi.org/10.1016/j.tria.2017.10.002.

4. Zadeh JR, Buicko JL, Patel C, Kozol R, Lopez-Viego MA. Grynfeltt hernia: a deceptive lumbar mass with a Lipoma-like presentation. Case Rep Surg. 2015;2015:954804. https://doi.org/10.1155/2015/954804.

5. Orcutt TW. Ann Surg. 1971;173(2):294-7. https://doi.org/10.1097/00000658197102000-00018.

6. Scheffler M, Renard J, Bucher P, Botsikas D. Incarcerated GrynfelttLesshaft hernia. J Radiol Case Rep. 2015;9(4):9-13. https://doi.org/10. 3941/jrcr.v9i4.2073.

7. Ahmed ST, Ranjan R, Saha SB, Singh B. Lumbar hernia: a diagnostic dilemma. BMJ Case Rep. 2014;2014:bcr2013202085. https://doi.org/10.1136/ bcr-2013-202085.

8. Ploneda-Valencia CF, Cordero-Estrada E, Castañeda-González LG, SainzEscarrega VH, Varela-Muñoz O, De la Cerda-Trujillo LF, et al. Grynfelt-Lesshaft hernia a case report and review of the literature. Ann Med Surg (Lond). 2016;7:104-6. https://doi.org/10.1016/j.amsu.2016.04.002.

9. Armstrong O, Hamel A, Grignon B, NDoye JM, Hamel O, Robert R, et al. Lumbar hernia: anatomical basis and clinical aspects. Surg Radiol Anat. 2008; 30(7):533-7; discussion 609-10. https://doi.org/10.1007/s00276-008-0361-2.

10. Hide IG, Pike EE, Uberoi R. Lumbar hernia: a rare cause of large bowel obstruction. Postgrad Med J. 1999;75(882):231-2. https://doi.org/10.1136/ pgmj.75.882.231

11. Moreno-Egea A, Baena EG, Calle MC, Martínez JA, Albasini JL. Controversies in the current management of lumbar hernias. Arch Surg. 2007;142(1):82-8. https://doi.org/10.1001/archsurg. 142.1.82.

12. Mingolla GP, Amelio G. Lumbar hernia misdiagnosed as a subcutaneous lipoma: a case report. J Med Case Rep. 2009;3:9322. https://doi.org/10.1186/ 1752-1947-3-9322.

13. Kadler B, Shetye A, Patten DK, Al-Nowfal A. A primary inferior lumbar hernia misdiagnosed as a lipoma. Ann R Coll Surg Engl. 2019;101(4):e96-8. https:// doi.org/10.1308/rcsann.2019.0009.

14. Stupalkowska W, Powell-Brett SF, Krijgsman B. Grynfeltt-Lesshaft lumbar hernia: a rare cause of bowel obstruction misdiagnosed as a lipoma. J Surg Case Rep. 2017;2017(9):rjx173. https://doi.org/10.1093/jscr/rjx173.

15. Hafner CD, Wylie JH, Brush BE. Petit's lumbar hernia: repair with Marlex mesh. Arch Surg. 1963:86:180-6. https://doi.org/10.1001/archsurg.1963. 01310080004002.

16. Mekonnen AG, Gonfa KB. Primary superior lumbar hernia: a rare cause of lumbar swelling. Int Med Case Rep J. 2019;12:67-70. https://doi.org/10.2147/ IMCRJ.S178727.

17. Stamatiou D, Skandalakis JE, Skandalakis LJ, Mirilas P. Lumbar hernia: surgical anatomy, embryology, and technique of repair. Am Surg. 2009:75(3):202-7.

18. Presti JC Jr, Narayan P. Lumbar herniation of the kidney. J Urol. 1988;140: 586-7. https://doi.org/10.1016/S0022-5347(17)41726-5.

19. Fogarty JD, Hafron JM, Melman A. Renal obstruction caused by herniation of renal pelvis and ureteropelvic junction through superior lumbar triangle hernia (Grynfeltt hernia). Urology. 2006;67(3):620-1. https://doi.org/10.1016/j. urology.2005.09.027

20. Cabello R, Cancho MJ, Monzó JI, López I, Tabares J, Hernández C. Herniation of renal pelvis and ureteropelvic junction resulting from superior lumbar triangle hernia. Scand J Urol Nephrol. 2008:42(1):81-2. https://doi.org/10. 1080/00365590701514589

21. Miyazato M, Yamada S, Kaiho Y, Ito A, Ishidoya S, Arai Y. Lumbar incisional hernia of the kidney after laparoscopic adrenalectomy in a patient with Cushing's syndrome. Urol Int. 2011;87(3):369-71. https://doi.org/10.1159/ 000329284. 
22. Al Hooti Q, Saleh AA, Mahfooz AB, Aslam M, Moazin M. Kidney herniation through lumbar triangle following open pyeloplasty. J Health Spec. 2014;2: 24-5. https://doi.org/10.4103/1658-600X.126061.

23. Vagholkar K, Vagholkar S. Open approach to primary lumbar hernia repair: a lucid option. Case Rep Surg. 2017;2017:5839491. https://doi.org/10.1155/ 2017/5839491.

24. Moreno-Egea A, Torralba-Martinez JA, Morales G, Fernández T, Girela E, Aguayo-Albasini JL. Open vs laparoscopic repair of secondary lumbar hernias: a prospective nonrandomized study. Surg Endosc. 2005;19(2):184-7. https://doi.org/10.1007/s00464-004-9067-7.

25. Moreno-Egea A, Alcaraz AC, Cuervo MC. Surgical options in lumbar hernia: laparoscopic versus open repair. A long-term prospective study. Surg Innov. 2013;20(4):331-44. https://doi.org/10.1177/1553350612458726.

\section{Publisher's Note}

Springer Nature remains neutral with regard to jurisdictional claims in published maps and institutional affiliations.

Ready to submit your research? Choose BMC and benefit from:

- fast, convenient online submission

- thorough peer review by experienced researchers in your field

- rapid publication on acceptance

- support for research data, including large and complex data types

- gold Open Access which fosters wider collaboration and increased citations

- maximum visibility for your research: over $100 \mathrm{M}$ website views per year

At BMC, research is always in progress.

Learn more biomedcentral.com/submissions 